\title{
A Case Report on Colistin Induced Myasthenia Gravis
}

\section{Pulimi Divya Priyanka ${ }^{1 *}$, Vithya Alhas ${ }^{1}$, Farhan $^{1}$ and Manoharan ${ }^{2}$, Shankar Prasad ${ }^{2}$, Shobha Rani R $\mathbf{H}^{1}$}

\author{
${ }^{1}$ Department of Pharmacy Practice, Al-Ameen College of Pharmacy, Bangalore, India \\ ${ }^{2}$ Department of Nephrology, St. Philomena's Hospital, Bangalore, India \\ *Corresponding Author: Pulimi Divya Priyanka, Department of Pharmacy Practice, \\ Al-Ameen College of Pharmacy, Bangalore, India.
}

Received: March 20, 2020

Published: June 30, 2020

(C) All rights are reserved by Pulimi Divya

Priyanka., et al.

\begin{abstract}
A 60-year-old Male got admitted to Surgical ward of tertiary care hospital with the complaints of wound debarment on left leg and left thigh abscess since two months and foul smell from 15 days associated with complaints of pain in both lower limbs. He is a known case of Type II DM from 10 years, HTN since one year, CLD, CKD from one and half year and on hemodialysis with oral medications. After adequate preoperative work up, the patient was taken for surgery with high risk and underwent skin grafting and withstood the surgery. The patient culture reported growth of Pseudomonas aeruginosa and on first day IV Colistin 1 Million Units TID, IV Clindamycin $600 \mathrm{mg}$ BD and IV Meropenem 1 gm TID were prescribed. The patient developed Myasthenia gravis and Neurologist confirmed it as Colistin induced and the same was stopped on 13th day. Neostigmine $2.5 \mathrm{mg}$ BD was prescribed and extubated. He was treated with other antibiotics and supportive treatment. Patient improved symptomatically after the withdrawal of Colistin and discharged in a stable condition with multivitamins, Anti-Hypertensives and Anti-Diabetic medications.

Keywords: Colistin; Myasthenia Gravis; Neostigmine
\end{abstract}

\section{Abbreviations}

DM: Diabetes Mellitus; HTN: Hypertension; CLD: Chronic Liver Disease; CKD: Chronic Kidney Disease

\section{Introduction}

Multidrug-resistant Gram-negative bacteria causing severe infections has become a major problem. In recent years the shortage of new antibiotics to combat the super bugs has led to the re-evaluation of polymyxins. These polypeptide bactericidal antibiotics were discovered from different species of Bacillus polymyxa in 1947; in practical use only two, polymyxin B and E (colistin) are been prescribed. The use of polymyxins have shown effectiveness in the treatment of infections due to susceptible Gram-negative bacteria, including Pseudomonas aeruginosa and Acinetobacter baumannii. However, their use was abandoned, except in patients with cystic fibrosis, because of concerns related to toxicity [1].

In recent reviews on toxicity of polymyxin Nephrotoxicity and neurotoxicity are associated more. Incidence of Neurotoxicity have become more common. The neurotoxic effects of polymyxins are usually mild and resolve after prompt discontinuation of the antibiotics. Lately in recent literatures cases of neuromuscular blockade and apnea have been reported.
Myasthenia gravis (MG) is a neuromuscular disorder characterized by weakness and fatigability of skeletal muscles. The underlying defect is a decrease in the number of available acetylcholine receptors (AChRs) at neuromuscular junctions due to an antibodymediated autoimmune attack. Treatment now available for MG is highly effective, although a specific cure has remained elusive [2].

\section{Case Report}

A 60-year-old Male got admitted to Surgical ward of tertiary care hospital with the complaints of wound debarment on left leg and left thigh abscess since two months and foul smell from 15 days associated with complaints of pain in both lower limbs. He is a known case of Type II DM from 10 years, HTN since one year, CLD, CKD from one and half year and on hemodialysis with oral medications.

Patient on the first day was conscious and oriented, Vitals were checked and were found to have BP 100/80 mmHg, Pulse Rate: 80 bpm. He was prescribed with T. Lasix $40 \mathrm{mg}$ BD, T. Globac-Z OD, T. Amiodarone $100 \mathrm{mg} \mathrm{BD}, \mathrm{T}$. Ubikar OD, T. CilaHeart $5 \mathrm{mg}$ OD, T. Metolazone $2.5 \mathrm{mg}$ OD, Inj. Colistin with $50 \mathrm{ml}$ NS TID, T. Clindamycin $300 \mathrm{mg}$ BD. 
Day 2: Patient had another wound on the left leg with foul smell with vitals stable. Patient was advised for dialysis.

Day 3: Patient had no fresh complaints and was posted for skin grafting secondary to suturing and wound debrident. His vitals were stable and laboratory investigation had Hemoglobin 7.9 gm\%, S. Creatinine was $2.5 \mathrm{mg} / \mathrm{dL}$.

Day 4: Patient's vital was stable and posted for surgery. With $\mathrm{Hb}-8.1$ gm\%, S. Urea - $35 \mathrm{mmol} / \mathrm{L}$.

Day 5: Patient was afebrile. With Hb - 8.2 g\%, S. Cr - 2.62 mg/dL. Culture test revealed presence of Pseudomonas aeruginosa. Advice to continue same treatment.

Day 6: Patient had a complain of pain over surgical area, and necessary management was performed. The patients vitals were stable with S. Cr- $3.09 \mathrm{mg} / \mathrm{dL}$, S. Urea - $56 \mathrm{mmol} / \mathrm{L}$

Day 7: Patient pain at surgical area was reduced and advised to continue treatment with wound dressing. Advice to dress the wound and continue treatment.

Day 8: Patient complained of giddiness, generalized weakness. Patients vital were stable and S. Cr $-2.72 \mathrm{mg} / \mathrm{dL}$. Advice to withhold T. Metolazone $2.5 \mathrm{mg}$ and add Inj. Clexane $60 \mathrm{mg}$ OD and T. Hosit OD. Patient was sent for dialysis.

Day 9: Patient had disturbed sleep. Patient vitals stable and was advised to continue same treatment.

Day 10: Patient had an episode of cardiac arrest in the morning and CPR was given for 5 cycles and was put on ventilator in ICU and started with inj.meropenem .

Day 11: Patient was stable but had altered sensorium. Advice to monitor patient closely and increase Inj. Clindamycin to $600 \mathrm{mg}$ TID.

Day 12: Patient was on guarded prognosis and ionotropic support (Nor Adrenaline $5 \mathrm{ml} / \mathrm{hr}$ ).Patient was drowsy but arousable and obeying simple commands with BP 80/70 mmHg, HR - 65 bpm and S.Cr - $3.59 \mathrm{mg} / \mathrm{dL}$, Potassium - $5.2 \mathrm{mmol} / \mathrm{L}$. Advice to reduce Inj. Lasix to $20 \mathrm{mg} \mathrm{BD}$ and refer to neurologist.

Day 13: Patient was conscious and obeying command and had complain of hematuria with $\mathrm{S}$. $\mathrm{Cr}-4.05 \mathrm{mg} / \mathrm{dL}$. Patient was advised to start on Inj. Calcium gluconate $1 \mathrm{amp}$ and Inj. Neostigmine 2.5 $\mathrm{mg}$ and Glycopylorate $0.4 \mathrm{mg}$ and extubated. Advice to stop Inj. Colistin and Inj. Clindamycin.
Day 14: Patient was on Ventilator CPAP. Laboratory investigation revealed $\mathrm{Hb}-6.9 \mathrm{gm} \%$, Ionized Calcium: $5.32 \mathrm{mmol} / \mathrm{L}$, S. Potassium- $3.7 \mathrm{mmol} / \mathrm{L}$. Advised to stop Inj. Clexane.

Day 15: Patient was diagnosed with Colistin induced Myasthenia gravis. Patient was conscious and oriented and dialysis was carried out in ICU.

Day 16: Patient was feeling. Routine laboratory test had S. Cr $2.9 \mathrm{mg} / \mathrm{dL}$. Advice to continue same treatment.

Day 17: Patient was stable and reduced sensorium but complaining of loose stool ( 8 episodes). Advised T. Loperamide $2 \mathrm{mg}$ SOS and T. Rigafut $200 \mathrm{mg}$ TID and stop Inj. Lasix $20 \mathrm{mg}$ and T. Amiodarone $100 \mathrm{mg}$.

Day 18: Patient was stable with reduced loose stools and was advised to stop Inj. Meropenem.

Day 19: Patient was afebrile. He was planned for discharge and was advised to follow diabetic diet and continue treatment as per the prescription.

Patient was discharged with, T. Globac -Z OD, T. Cardarone 100 mg BD, T. CilaHeart 5 mg OD, T. Lasix 20 mg BD, T. Ubikar OD, T. Ecosprin Gold OD, T. Carvidalol 3.125 mg BD, T. Duonem 200 mg BD ( 5 days). He was advised to review after a week under Nephrologist and Neurologist.

\section{Discussion and Conclusion}

In the afore-mentioned case, the patient showed the symptoms of generalized weakness and sensorium.

The prognosis of Myasthenia gravis has improved strikingly as a result of advances in treatment. Nearly all myasthenic patients can be returned to full productive lives with proper therapy. The most useful treatments for MG include anticholinesterase medications, immunosuppressive agents, thymectomy, and plasmapheresis or intravenous immunoglobulin (IVIg) [2].

The patient showed symptomatic improvement and was discharged. The opinions were taken from Neurologist, Pulmonologist and Surgeon.

Colistin (Polymyxin E) induced Myasthenia Gravis is a rare case and was diagnosed on time and treated accordingly.

Patient's condition improved day by day; He had a significant improvement and reduced symptoms on the day of discharge with no neuromuscular complications. 
The proper treatment and care with the timely diagnosis can prevent disease progression.

\section{Acknowledgment}

We thank our Medical Director of St. Philomena's Hospital, Bengaluru, Dr. Shankar Prasad and PGs at St. Philomena's Hospital.

\section{Conflict of Interest}

There are no conflict of interest.

\section{Bibliography}

1. Falagas ME and Kasiakou SK. "Toxicity of polymyxins: a systematic review of the evidence from old and recent studies". Critical Care (London, England) 10.1 (2006): R27.

2. Kasper D and Harrison T. "Harrison's principles of internal medicine". $19^{\text {th }}$ edition. New York: McGraw-Hill, Medical Publication. Division (2015).

\section{Assets from publication with us}

- Prompt Acknowledgement after receiving the article

- Thorough Double blinded peer review

- Rapid Publication

- Issue of Publication Certificate

- High visibility of your Published work

Website: www.actascientific.com/

Submit Article: www.actascientific.com/submission.php Email us: editor@actascientific.com

Contact us: +919182824667 